\title{
MEIO AMBIENTE NA AGENDA INTERNACIONAL E A SUA CONSAGRAÇÃO COMO UM DIREITO HUMANO NA JURISPRUDÊNCIA DO SISTEMA INTERAMERICANO
}

\author{
Rafael Antonietti Matthes \\ rafael.matthes@hotmail.com \\ Mestrando em Direito Ambiental pela \\ Universidade Católica de Santos e Pós- \\ Graduado em Direito Internacional \\ pela PUCSP. Bolsista da CAPES \\ Maria Luiza Machado Granziera \\ Marialuiza.granziera@gmail.com \\ Mestre e Doutora pela FADUSP. \\ Professora do PPGD da UNISANTOS. \\ Advogada e consultora em Direito \\ Ambiental. \\ Recebido em 26/02/3012 \\ Aprovado em 15/10/2012
}

\section{Resumo}

A incorporação da temática ambiental no âmbito das entidades internacionais voltadas à proteção dos direitos humanos vem sendo construída paulatinamente, por meio de resoluções específicas e de decisões jurisdicionais. Essa inclusão é fundamental, na medida em que as questões ambientais estão diretamente relacionadas com os direitos humanos, seja no que diz respeito à saúde, integridade física, cultura, seja em relação à proteção com uso dos recursos naturais para as presentes e futuras gerações. Este trabalho aborda a incorporação do direito ao meio ambiente no âmbito do Sistema Interamericano de Proteção aos Direitos Humanos.

Palavras - chave:

Direitos humanos; meio ambiente; Comissão Interamericana de Direitos Humanos; Corte Interamericana de Direitos Humanos. 


\title{
ENVIRONMENT IN THE INTERNATIONAL AGENDA AND ITS CONSECRATION AS A HUMAN RIGHT IN THE JURISPRUDENCE OF THE INTER- AMERICAN SYSTEM
}

\author{
Rafael Antonietti Matthes \\ Maria Luiza Machado Granziera
}

ABSTR ACT

Environmental issues have been gradually incorporated to the framework of international entities related to the protection of human rights. Specific resolutions and judicial decisions are the tools used to their implementation. This inclusion is fundamental because environmental issues are directly related to buman rights, whether with regard to physical integrity, health, culture, whether in relation to the protection and with use of natural resources for present

and future generations. This work discusses the incorporation of the right to the environment within the framework of the Inter-American System of Protection for Human Rights.

Key words:

Human rights; environment; Inter-American Commission on Human Rights; InterAmerican Court of Human Rights. 


\section{SUMÁRIO}

Introdução

1. Meio ambiente como compromisso da agenda internacional

1.1. Degradação ambiental e as fronteiras nacionais

1.2. Conferências internacionais da ONU em matéria ambiental

1.3. A consagração do meio ambiente ecologicamente equilibrado com um direito humano

2. O Sistema Interamericano de Proteção aos Direitos Humanos

2.1. Evolução histórica do Sistema Interamericano

2.2. Comissão Interamericana de Direitos Humanos

2.3. Corte Interamericana de Direitos Humanos

2.4. O Direito ao Meio Ambiente Sadio no Sistema Interamericano

2.5. Meio ambiente na jurisprudência do Sistema Interamericano

Conclusão - Referencias bibliográficas. 


\section{INTRODUÇÃO}

Com o passar dos anos, a associação do meio ambiente com o tema dos direitos humanos consagrou-se em nível mundial. Debates e conferências especializadas sobre tais temas foram realizados no âmbito da ONU e de seus comitês, resultando em normas de proteção internacional. Trata-se de uma nova forma de abordar os direitos humanos, associando-os às importantes questões relativas aos impactos que as atividades humanas vêm impondo à natureza e, consequentemente, à vida.

Segundo Norma Sueli Padilha ${ }^{1}$ não bastam direitos humanos de liberdade (primeira dimensão) e de igualdade (segunda dimensão), pois para se conquistar condições de vida sadia, é imprescindível a manutenção do equilíbrio do meio ambiente, cuja qualidade permita uma vida de dignidade e bem-estar, enquanto um direito humano de fraternidade, que impõe, inclusive a responsabilidade das atuais gerações para com as futuras. O meio ambiente ecologicamente equilibrado é, pois, necessário ao ser humano na medida em que fornece as bases para o crescimento e desenvolvimento não apenas de suas atividades e a garantia de sua saúde, bem como do resgate da interação do homem com a natureza.

A finalidade deste artigo é indicar as bases de associação, no âmbito do Sistema Interamericano de Proteção aos Direitos Humanos, do direito ao meio ambiente ecologicamente equilibrado e os direitos humanos, que não podem mais ser entendidos separadamente. Segundo Peter Quilter ${ }^{2}$, "apesar de até recentemente esses campos terem sido vistos como distintos, a prática cada vez mais os vincula".

Após uma sucinta evolução histórica do Sistema, caberá analisar seus principais órgãos de proteção e a exposição de seus procedimentos, além da jurisprudência especializada.

PADILHA, Norma Sueli. Fundamentos constitucionais do direito ambiental. Rio de Janeiro: Campos, 2010, p. 123

2 QUILTER, Peter. Relatório da Secretaria - Geral sobre Cumprimento da AG/RES 1819(XXXI-0/01) Direitos Humanos e Meio Ambiente. Conselho Permanente da Organização dos Estados Americanos, 2002, p. 1 


\section{Meio ambiente como compromisso da agenda internacional}

\subsection{Degradação ambiental e as fronteiras nacionais}

Expressões como efeito estuda, poluição, degradação da camada de ozônio, degelo de calotas polares e desaparecimento de cidades litorâneas, como Veneza, estão cada vez mais frequentes nos noticiários matinais, nos discursos dos grandes líderes e até mesmo nos desenhos animados.

Apesar de serem fenômenos causados por motivos diversos, todos eles estão inter-relacionados quando a palavra-chave é degradação do meio ambiente.

O efeito estufa, por exemplo, diferentemente do que muitos pensam, é um processo normal e inevitável para sadia qualidade de vida. Trata-se de um fenômeno, por meio do qual parte da radiação infravermelha emitida pela superfície terrestre e é absorvida por determinados gases presentes na atmosfera. Tal processo se torna catastrófico, quando os seus fatores: emissão de gases e retenção de calor, se elevam e geram um desequilíbrio, acarretando o chamado aquecimento global.

A camada de ozônio, por sua vez, é uma fina camada de gás chamado ozônio (O3), que protege as vidas terrestres do calor emitido pelo sol, ou seja, dos chamados raios ultravioletas. Esse verdadeiro "filtro solar" da terra, está se degradando, paulatinamente, principalmente em razão da grande emissão de gases clorofluorcarbonos (CFCs) na camada terrestre. Para se ter uma ideia, quando estes gases entram em contato a radiação ultravioleta, acabam por liberar outro gás, denominado de cloro. Este, por sua vez, ao interagir com o ozônio, o transforma em gás oxigênio, resultando em um verdadeiro buraco na camada, que permitirá que os raios atinjam a população terrestre.

Juntamente com os outros fenômenos descritos no primeiro parágrafo, todos são resultado da degradação ambiental. Esses graves problemas, no entanto, conforme explicitado pelo professor Mestre José Eduardo Ramos Rodrigues, na obra organizada pelos professores doutores Cristiane Derani e José Augusto Fontoura Costa ${ }^{3}$ " "não põe em risco apenas interesses pecuniários individuais ou de determinadas classes sociais de alguns países, (...) mas a sobrevivência de toda a humanidade e da vida como a conhecemos".

A partir do momento em que a sociedade tomou conhecimento dessa natureza transfronteiriça dos danos ambientais, seus combates passaram a ser de interesse de todos os países soberanos, deixando de ser apenas uma questão interna, para ser uma preocupação global.

3 COSTA, José Augusto Fontoura e DERANI, Cristiane. Direito Ambiental Internacional. Santos: Leopóldianun, 2001, p. 7 
Foi nesses termos, que o Direito Internacional, que "tradicionalmente regula, como objetivo central, as relações existentes entre Estados", tornou-se um importante sistema regulatório de questões ambientais".

O professor pós-doutor Valério Mazzuoli ${ }^{5}$ ilustra bem como o meio ambiente passou a ser importante na agenda internacional. Em suas palavras:

Tais matérias (Direitos Humanos e Meio Ambiente), ao lado da democracia, passaram a marcar, de maneira ampla e inovadora, a nova agenda internacional do século XXI, notadamente pós as grandes mudanças ocorridas no mundo em virtude do processo de globalização, cujos reflexos são marcantes e decisivos para o entendimento dos novos fenômenos globais surgidos no planeta a partir de então.

Vale ressaltar, que esse modo de regulação internacional, se dá de forma coordenada: não há poder central que regule todos os estados. Estes mantêm suas soberanias e atuam com cooperação, respeito recíproco, culminando na realização de tarefas e cumprimento de metas comuns. Mais uma vez, vale lembrar dos ensinamentos de Costa e Derani ${ }^{6}:$ :

As relações de cooperação (presentes no artigo $1, \$ 3^{\circ}$ da Carta das Nações Unidas), por seu turno, pressupõem a coordenação de esforços para metas consideradas comuns pelos Estados. Ainda assim, no entanto, a soberania estatal se mantém inatingível. A coordenação interestatal pressupõe a coexistência, a não intervenção e a independência.

Assim, considerando esse caráter cooperativo do direito internacional, a emergência de uma proteção global do assunto, levou os estados soberanos a se reunirem por diversas vezes em conferência internacionais organizadas com os auspícios da Organização das Nações Unidas.

4 COSTA, José Augusto Fontoura e DERANI, Cristiane. Direito Ambiental Internacional. Santos: Leopóldianun, 2001, p. 7

5 MAZZUOLI, Valério de Oliveira. Curso de Direito Internacional Público. 3a. ed. ,São Paulo: Revista dos Tribunais, 2009, p. 859

6 COSTA, José Augusto Fontoura e DERANI, Cristiane. Direito Ambiental Internacional. Santos: Leopóldianun, 2001, p. 7 


\subsection{Conferências internacionais da ONU em matéria ambiental}

Constituída em 24 de outubro de 1945, após a entrada em vigor internacional da chamada Carta da Organização das Nações Unidas, a ONU foi criada com a intenção, dentre outras, de preservar as gerações futuras dos flagelos da guerra e reafirmar a fé nos direitos fundamentais do homem, da dignidade e no valor do ser humano, na igualdade de direito dos homens e das mulheres, assim como das nações grandes e pequenas?

Dentro do seu âmbito de atuação, a ONU possui diversos órgãos especializados e realiza uma vez por ano, ordinariamente, Assembléia-Geral, para discutir e fazer recomendações relativamente a qualquer matéria que for objeto da Carta ou se relacionarem com as atribuições e funções de qualquer dos órgãos nela previstos.

É neste cenário de cooperação, que foram realizadas diversas conferências internacionais sobre meio ambiente, no âmbito das Nações Unidas.

Primeiramente, os países se reuniram em Estocolmo, entre os dias 5 e 16 de junho de 1972, na maior conferência internacional organizada até então. Lá, alguns documentos internacionais foram ratificados e diversos princípios consagrados, dentre eles o do Direito Humano ao Meio Ambiente, disciplinado no artigo $1^{\circ}$ da Convenção de Estocolmo.

A professora Pós-Doutora em Direito Solange Teles da Silva ${ }^{8}$, explicita a importância dessa reunião, para o desenvolvimento de um novo ramo do Direito, o chamado Direito Ambiental Internacional:

A nova dinâmica estabelecida, notadamente, o reconhecimento da existência da problemática ambiental e da necessidade de agir por parte dos Estados e os resultados da conferência tiveram um enorme impacto no desenvolvimento do direito ambiental internacional,

Após a Estocolmo 72, diversas convenções multilaterais foram adotadas revelando uma nova postura mundial de conservação da natureza, de proteção dos mares e oceanos, bem como de enfrentamento de novos tipos de poluição, como, por exemplo, a Convenção de Londres sobre a Preservação da Poluição Marinha por Alijamento de Resíduos (1972); a Convenção sobre Comércio Internacional de Espécies da Flora e da Fauna Selvagens em Perigo de Extinção (CITES - 1973); a Convenção sobre direito do mar (1982); a Convenção de Viena para a proteção da Camada de Ozônio (1985); entre outras.

\footnotetext{
Preâmbulo da Carta da Organização das Nações Unidas.

8 SILVA, Solange Teles da. O Direito Ambiental Internacional. Belo Horizonte: Del Rey, 2010, p. 28
} 
Vale lembrar, no entanto, que apesar da crescente preocupação com a matéria ambiental, "os progressos nesse período foram insuficientes para alterar a destruição do meio ambiente. De acordo com uma avaliação realizada pelo PNUMA (...), em 1982, os problemas ambientais tinham piorado"'.

Assim, já em 1983, preocupada com essa piora na qualidade do meio ambiente, a Assembléia-Geral da ONU criou a Comissão Mundial sobre Meio Ambiente e Desenvolvimento, presidida pela então Primeira Ministra da Noruega, Gro Harlem Brundtland.

Após anos de discussões e debates, a Comissão, em 1987, entregou à Assembléia-Geral da ONU, um relatório denominado Nosso Futuro Comum ou Relatório Brundtland, o qual afirmava a necessidade de entrar em uma nova era de crescimento econômico apoiado em práticas que conservassem e expandissem a base dos recursos ambientais.

Restou a consagrada ideia da sustentabilidade, ou seja o desafio global de proteção ao meio ambiente não mais podia se dissociar das questões relativas ao desenvolvimento econômico e social. Por meio desse relatório, a expressão desenvolvimento sustentável restou assim conceituada ${ }^{10}$ :

Em essência, o desenvolvimento sustentável é um processo de transformação no qual a exploração dos recursos, na direção dos investimentos, a orientação do desenvolvimento tecnológico e a mudança institucional se harmonizam e reforçam o potencial presente e futuro, a fim de atender às necessidades e aspirações humanas.

Apoiada nessa ideia, em 1992, foi realizada a $2^{a}$ grande conferência em matéria ambiental, nos quadros da ONU, a chamada Conferência do Rio de Janeiro sobre Meio Ambiente e Desenvolvimento, ou "Cúpula da Terra" ou, também, ECO/92.

Nesta, compareceram 100 chefes de Estado, além de delegados, organizações intergovernamentais e representantes de organizações não governamentais, o que demonstra sua grandeza e importância. Seu objetivo era catalisar a cooperação internacional em prol de ações concretas para conciliar o desenvolvimento econômico, com a proteção ambiental, nos exatos termos do supracitado Relatório Brundtland.

Após calorosos debates, três documentos jurídicos foram aprovados, são eles: a Declaração do Rio, a Agenda 21 e a Declaração sobre Florestas. Além desses, duas convenções foram abertas à assinatura: a Convenção-Quadro das Nações

$9 \quad$ SILVA, Solange Teles da. O Direito Ambiental Internacional. Belo Horizonte: Del Rey, 2010, p. 28

10 COMISSÃO MUNDIAL SOBRE MEIO AMBIENTE E DESENVOLVIMENTO. Nosso futuro

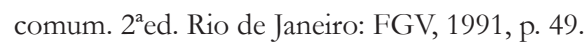


Unidas sobre Mudança do Clima e a Convenção-Quadro das Nações Unidas sobre Diversidade Biológica.

Dentre esses acordos firmados e abertos à assinatura, vale citar que a Convenção-Quadro das Nações Unidas sobre Mudança Climática criou a chamada Conferência das Partes (COPs), cujo objetivo é adotar instrumentos legais e conseguir, nos termos das disposições relevantes da Convenção, estabilizar as concentrações na atmosfera de gases com efeito de estufa a um nível que evite uma interferência antropogénica perigosa com o sistema climático ${ }^{11}$.

As COPs são realizadas, anualmente, desde 1995 - um ano após a entrada em vigor da Convenção supracitada. Dentre as principais, vale citar a COP-3, realizada em Quioto, Japão, cujo resultado foi a criação de um protocolo adicional à Convenção, mundialmente conhecido como Protocolo de Quioto.

Neste, percebe-se a clara aplicação do princípio do desenvolvimento sustentável, já que restou consignada a criação de um mercado de carbono (instrumento econômico), dentre os mecanismos de flexibilização, para que os países signatários alcançassem seus objetivos de redução de emissão de gases poluentes, ou seja, alcançassem suas metas de proteção ambiental.

No decorrer de todas as outras COPs, outros acordos foram firmados e os princípios do desenvolvimento sustentável e do poluidor-pagador ganharam força na medida em que a economia começou a pautar os debates.

Com o objetivo de verificar o andamento da implantação dos princípios estabelecidos em 1992, na Conferência do Rio, a ONU promoveu, em 2002, outro evento de âmbito mundial para discutir questões ambientais e desenvolvimento sustentável.

A Conferência de Johanesburgo ou RIO +10 abordou diversos temas como acesso à energia limpa e renovável, as consequências do efeito estufa, a conservação da biodiversidade, a proteção e uso das águas, o acesso à água potável e ao saneamento básico até 2015.

Como resultado, foi criada uma Declaração Política, por meio da qual, os países signatários reafirmaram os princípios das Declarações de Estocolmo e do Rio de Janeiro, e um Plano de Implementação, que reforçou a necessidade de equilíbrio entre os pilares do desenvolvimento sustentável (economia, sociedade e meio ambiente).

11 Artigo $2^{\circ}$ da Convenção Quadro das Nações Unidas sobre Mudanças Climáticas. 
Após a edição dessas três grandes conferências ambientais e da criação de diversos acordos multilaterias, atualmente, a sociedade internacional está na expectativa da realização da chamada Rio + 20, em junho 2012.

Espera-se, ansiosamente, neste encontro, que os países possam discutir com especialistas e com representantes de organizações internacionais, de ONGs e da sociedade, não só temas que foram veiculados em 1992, mas também, fatos novos e que merecem atenção, ou seja, espera-se, em geral, que as decisões tomadas sejam mais do que um balanço dos últimos 20 anos, sejam efetivas, atuais, sustentáveis e demonstrem a urgência da proteção ambiental.

\subsection{A consagração do meio ambiente ecologicamente equilibrado com um direito humano}

Apesar das preocupações econômicas, a relação do meio ambiente com os direitos humanos consagrou-se a patamares globais e diversas constituições federais, dentre elas a brasileira, reconheceram a questão ambiental como um verdadeiro direito fundamental.

Todavia, em que pese a prática já ter inter-relacionado tais direitos, muitos autores de renome internacional, e com eles alguns países de tendências nada progressistas, insistem na ideia de que a ausência do termo meio ambiente na Declaração Universal dos Direitos Humanos de 1948, constituiu um verdadeiro óbice a tal comunhão de direitos.

Para estes, a inter-relação se aflora apenas quando o dano ao meio ambiente de fato afeta os direitos humanos das pessoas. Assim, é possível dizer que duas correntes surgem na doutrina especializada: esta, em que a relação e a solução é meramente processual e outra em que as soluções decorrem da relação substantiva das duas áreas.

A substantiva abrange, essencialmente, a nova legislação que conscientemente junta os dois assuntos de maneira declaratória.

Deve-se ressaltar, primeiramente, o contexto histórico da elaboração da referida declaração. Naquela época, discutia-se outros problemas, e a luta era pela paz universal. Os países haviam passado por duas longas guerras mundiais e o mundo estava horrorizado com as atrocidades que os homens podem cometer para alcançar seus mais gananciosos objetivos. 
Não há dúvidas, que se tal Declaração fosse escrita e promulgada nos dias atuais, após diversas reuniões no âmbito da ONU e de até debates sobre a matéria no Conselho de Segurança, a redação seria diferente e o meio ambiente estaria entre os descritos naquele documento.

Outro ponto que merece destaque diz respeito a duas características dos direitos humanos, qual sejam, a inexauribilidade e a historicidade. De acordo com estas, os direitos humanos tem possibilidade de expansão, juntamente com a evolução histórica.

Nesses termos, está o entendimento do professor José Afonso da Silva ${ }^{12}$ : a Declaração de Estocolmo 72, "abriu caminho para que as Constituições supervenientes reconhecessem o meio ambiente ecologicamente equilibrado como um direito humano fundamental entre os direitos sociais do homem".

Por fim, outra solução para controvérsia apresentada acima é a chamada teoria do ricochete. De acordo com essa, o direito ao meio ambiente sadio pode ser considerado um direito humano decorrente de outro já consagrado na Declaração, como no caso do direto à vida.

A questão se mostra muito atual, mas não se pode negar que o meio ambiente ganhou força de direito humano no momento em que passou a ser discutido no âmbito da ONU, principal órgão de promoção desses direitos. Além disso, hoje, o direito ambiental, como se verá nos próximos capítulos, já pode ser causa de pedir em uma demanda protocolada no Sistema Interamericano de Proteção aos Direitos Humanos.

Assim, tanto a práxis, quanto a jurisprudência, demonstram a elevação do meio ambiente como algo inerente a todos os seres humanos. Sua proteção garante entre outras coisas, os próprios direitos consagrados em 1948 na Declaração, já que não haverá vida, cultura, educação e até mesmo trabalho digno, se o meio ambiente não estiver preservado.

12 SILVA, José Afonso da. Curso de Direito Constitucional Positivo. 19a. Ed., São Paulo: Malheiros, 2000, p.67 


\section{O Sistema Interamericano de Proteção aos Direitos Humanos}

\subsection{Evolução histórica do Sistema Interamericano}

A doutrina majoritária aponta como principais características dos direitos humanos: a universalidade, a essencialidade, a irrenunciabilidade, a inalienabilidade, a inexauribilidade, a imprescritibilidade e a vedação ao retrocesso e a historicidade.

Quanto a esta última, vale lembrar que os direitos humanos são frutos de um processo histórico. Começaram a se desenvolver, em um plano internacional, a partir do final da Segunda Guerra Mundial, com o nascimento da Organização das Nações Unidas.

Em âmbito regional, após a evolução no plano global, os direitos humanos receberam proteção específica por meio dos sistemas europeu, africano e interamericano.

O chamado Sistema Interamericano de Proteção aos Direitos Humanos desenvolveu-se paralelamente ao princípio da solidariedade pan-americana. O pan- americanismo, por sua vez, pode ser entendido como um movimento de cooperação entre os países americanos, cujos principais objetivos eram: promover a paz no continente, preservar a independência dos Estados e estimular seu interrelacionamento.

Sobre o desenvolvimento gradual deste princípio em conjunto com a necessidade de criação de um sistema específico de proteção dos direitos humanos, vale citar os ensinamentos da professora Olaya Hanashiro ${ }^{13}$ que divide o período em três fases distintas:

Situada entre os anos de 1826 e 1889, a primeira fase tem início com o chamado Congresso do Panamá, um evento até então pioneiro, na busca de alternativas de cooperação entre os países americanos. Após o Congresso, os países participantes (Colômbia, Equador, Panamá, Venezuela, México, Peru e todos os países da América Central) firmaram o chamado "Tratado de União Perpétua, Liga e Confederação".

Dentre os principais pontos abordados nesse acordo, pode-se ressaltar: a) a criação de uma confederação dos Estados americanos para a consolidação da paz e da defesa solidária dos direitos dos países participantes; b) a defesa da independência política e integridade territorial dos membros; c) o princípio da democracia

13 HANASHIRO, O. S. M. P. O Sistema Interamericano de Proteção dos Direitos Humanos. São Paulo; EDUSP, 2001, p. 25 
representativa como condição sine qua non para pertencer à União; d) o princípio da cidadania continental (que estabelecia a igualdade jurídica entre os nacionais e os estrangeiros de um Estado), além de e) um compromisso de cooperação na abolição da escravatura.

Já a próxima fase, compreendida entre os anos de 1889 e 1945, caracterizouse pela realização de diversas conferências de Ministros das Relações Exteriores, em diferentes capitais da América. Dentre os principais resultados desses eventos, pode-se citar a criação da "União Internacional das Repúblicas Americanas", cuja função era reunir e divulgar informações comerciais de seus membros. Suas atividades eram cumpridas pela Secretaria da União chamada "Oficina Comercial". Durante a Quarta Conferência, esses nomes foram rebatizados respectivamente, como "União das Repúblicas Americanas" e "União Pan-americana".

Vale lembrar, que as atribuições iniciais da União Pan-americana foram, com o tempo, estendidas a tal ponto que, com a promulgação da Carta da Organização dos Estados Americanos (OEA), em 1948, foi transformada na Secretária-Geral da Organização.

Foi nesta fase ainda, que a preocupação com os direitos humanos ganhou contornos vultosos. Inicialmente, com a criação da Convenção Relativa aos Direitos do Estrangeiro, depois, enfatizou-se questões relativas à nacionalidade e ao asilo, e, por fim, debateu-se questões atinentes ao direito da mulher e à paz.

A terceira e última fase compreende o período do pós-guerra até os dias atuais. O primeiro grande evento desta fase foi a Conferência de Chapultepec, realizada no México, em 1945, cujo objetivo era debater os "Problemas da Guerra e da Paz". Esse evento deu início ao processo de institucionalização jurídica do sistema da OEA. Como lembra Hanashiro ${ }^{14}$ :

A Declaração do México reafirmou a adesão aos princípios democráticos e a necessidade de harmonizar-se os interesses da coletividade com os direitos individuais. Foram aprovadas resoluções sobre liberdade de informação, defesa e preservação da democracia no continente americano, proteção internacional dos direitos essenciais do homem, discriminação racial e princípios sócias das Américas. Ainda nessa conferência, foram preparados os projetos da Carta da OEA e da Declaração Americana dos Direitos Humanos, documentos que serviriam de base para a IX Conferência Internacional dos Estados Americanos que inaugurou, em 1948, o Sistema Interamericano de Proteção aos Direitos Humanos propriamente dito.

14 HANASHIRO, O. S. M. P. O Sistema Interamericano de Proteção dos Direitos Humanos. São Paulo; EDUSP, 2001, p. 27 
Por outro lado, o professor Valério Mazzuoli ${ }^{15}$ entende que o sistema de proteção dos direitos humanos tem sua origem histórica no ano de 1948, com a promulgação da Carta da Organização dos Estados Americanos (Carta de Bogotá), que foi aprovada na $9^{a}$ Conferência Interamericana.

Neste encontro internacional, lembra o professor que também foi celebrada a Declaração Americana dos Direitos e Deveres do Homem, que formou a base normativa de proteção no sistema interamericano anterior à conclusão da Convenção Americana em 1969.

A adoção destes dois instrumentos ensejou a criação dos chamados mecanismos de proteção dos direitos humanos no Sistema Interamericano: a Comissão Interamericana de Direitos Humanos, com sede no Chile, especializada na promoção e proteção dos direitos humanos no âmbito da OEA; e a Corte Interamericana de Direitos Humanos, com sede na Costa Rica, com jurisdição para emitir consultas ou agir de forma contenciosa.

\subsection{Comissão Interamericana de Direitos Humanos}

A Comissão foi criada, inicialmente, por meio da Resolução VIII da V Reunião de Consulta dos Ministros das Relações Exteriores, ocorrida em Santiago (Chile) em 1959, sendo que o seu funcionamento iniciou-se apenas em 1960.

Inicialmente, a proposta era de que essa Comissão iria funcionar apenas até a instituição de uma Convenção Interamericana sobre Direitos Humanos, que ocorreu em 1969, em São José, Costa Rica, no período de 7 a 22 de novembro. A Convenção, porém, não só manteve a Comissão como lhe atribuiu mais efetividade.

Representando todos os Estados-membros da OEA, a Comissão tem como finalidade precípua promover a observância e a defesa dos direitos humanos, exercendo para tanto as seguintes funções e atribuições (art. 41): a) estimular a consciência dos direitos humanos nos povos da América; b) formular recomendações aos governos dos Estados-membros, quando considerar conveniente, no sentido de que adotem medidas progressivas em prol dos direitos humanos no âmbito de suas leis internas e seu preceitos constitucionais, bem como disposições apropriadas para promover o devido respeito a esses direitos; c) preparar estudos ou relatórios que considerar convenientes para o desempenho de suas funções; d) solicitar aos governos dos Estados-membros que lhe proporcionem informações sobre as medidas que adotarem em matéria de direitos humanos (podendo, inclusive, realizar inspeções in loco nesses Estados); e) atender às consultas que, por meio

15 MAZZUOLI, Valério de Oliveira. Curso de Direito Internacional Público. 3a. ed. ,São Paulo: Revista dos Tribunais, 2009 , p. 807. 
da Secretaria-Geral da OEA, lhe formularem os Estados-membros sobre questões relacionadas com os direitos humanos e, dentro de suas possibilidades, prestarlhes $\mathrm{o}$ assessoramento que solicitarem; f) atuar com respeito às petições e outras comunicações, no exercício de sua autoridade, de conformidade com o disposto nos arts. 44 a 51 da Convenção Americana; e g) apresentar um relatório anual à Assembléia-Geral da OEA.

Dentre todas as atribuições descritas acima, destaca-se o juízo de admissibilidade realizado por esta, quando, nos termos do artigo 44, indivíduos, grupos de indivíduos, entidades não-governamentais legalmente reconhecidas em um ou mais Estados-membros da OEA comunicam, por meio de petições, violações de direitos humanos. Isso ocorre pelo fato de os indivíduos não terem acesso direto à Corte ${ }^{16}$.

Verifica-se, desta forma $a^{17}$, "a função de juízo de admissibilidade das demandas dirigidas à Corte, além de elaborar relatórios anuais para a Assembléia Geral”.

Por fim, no que tange à composição da Comissão, ressalta-se que é formada por sete membros, que necessariamente, devem ser pessoas de alta autoridade moral e de reconhecido saber em matéria de direitos humanos. Esses membros são eleitos para um mandato de quatro anos, pela Assembléia-Geral da OEA, a partir de uma lista de candidatos propostos pelos governos dos Estados-membros.

\subsection{Corte Interamericana de Direitos Humanos}

A criação de uma corte de justiça na região americana é um desejo antigo dos Estados. Para se ter uma ideia, em 1923, durante a V Conferência Pan-Americana, a delegação da Costa Rica propôs um projeto para a criação dessa corte. Apesar de a primeira tentativa restar infrutífera, após a promulgação da Convenção Americana, este órgão foi instituído.

A chamada Corte Interamericana de Direitos Humanos possui sua sede na própria Costa Rica e foi instalada oficialmente em 1979. Sua composição é de sete juízes, cujas nacionalidades são, obrigatoriamente, distintas, para exercerem um mandato de seis anos.

16 MAZZUOLI, Valério de Oliveira. Os Sistemas Regionais de Proteção dos Direitos Humanos: uma análise comparativa dos sistemas interamericano, europeu e africano. São Paulo: Revista dos Tribunais, 2011, (Coleção Direito e Ciências Afins, V. 9), p. 25.

17 DELGADO, Ana Paula Teixeira. O direito ao desenvolvimento na perspectiva da globalização. São Paulo: Renovar, 2001, p. 70. 
Nos termos do artigo 52 da Convenção, pode-se citar como requisitos para a investidura dos juízes, além dos descritos no parágrafo anterior: reconhecida alta autoridade moral; reconhecida competência em matéria de direitos humanos; e, posse das condições requeridas para o exercício das mais elevadas funções judiciais, nos termos da lei do estado do qual seja nacional ou do estado que os propuser como candidatos.

Quanto à sua jurisdição, atua tanto consultivamente, interpretando a Convenção e outros tratados em matéria de direitos humanos nos Estados americanos; como contenciosamente, julgando casos concretos, quando for alegada violação de preceitos da Convenção.

Apesar de prevista, a jurisdição contenciosa é limitada, já que para o seu exercício, é imprescindível que os Estados-membros da Convenção reconheçam expressamente esta jurisdição.

Quanto aos legitimados, diferentemente da Comissão, os particulares e as instituições privadas não podem ingressar diretamente com demandas ou consultas na Corte.

No que tange as decisões proferidas, nos termos do artigo 67 da Convenção, elas são definitivas e inapeláveis. Caso o Estado réu não aceite, espontaneamente, a decisão da Corte, vale citar os ensinamentos do professor Mazzuoli ${ }^{18}$.

Aqui devemos ressaltar que, se o Estado não cumprir o artigo 68 (1) da Convenção Americana (que ordena que os Estados aceitem, espontaneamente, as decisões da Corte), acarretará uma violação adicional da Convenção, possibilitando-se, portanto, no Sistema Interamericano, a possibilidade de um novo procedimento contencioso desse tipo contra aquele Estado ${ }^{19}$.

Sendo assim, nos termos do artigo 68(1), da Convenção Americana, o Estado que não cumprir a decisão da Corte, espontaneamente, poderá ser demandado em novo procedimento, sem que haja litispendência.

MAZZUOLI, Valério de Oliveira. Os Sistemas Regionais de Proteção dos Direitos Humanos: uma análise comparativa dos sistemas interamericano, europeu e africano. São Paulo: Revista dos Tribunais, 2011, (Coleção Direito e Ciências Afins, V. 9), p. 6

19 "Here we must emphasize that, if the State fails to observe Article 68(1) of the American Convention (which ordains that the States accept, sponte sua, the Court's decisions), it incurs a further violation of the Convention, thus activating in the Inter-American system the possibility of a new contentious procedure against such State.” (tradução nossa). 


\subsection{O Direito ao Meio Ambiente Sadio no Sistema Interamericano}

Conforme descrito no tópico 1.3, o Direito ao Meio Ambiente Sadio foi alçado, com o tempo, à condição de um Direito Humano internacionalmente protegido. Mais uma prova dessa consagração é encontrada tanto nas normativas adicionais à Convenção, quanto na jurisprudência da Corte.

Isso porque, nos termos do artigo 11 do Protocolo Adicional à Convenção Americana sobre Direitos Humanos em Matéria de Direitos Econômicos, Sociais e Culturais, "toda pessoa tem direito a viver em meio ambiente sadio e a contar com os serviços públicos básicos", cabendo aos Estados - Partes a promoção, proteção, preservação e melhoramento do meio ambiente.

Além deste Protocolo, outros documentos e resoluções descrevem a importância dada ao tema no âmbito do Sistema Interamericano de Direitos Humanos e da Organização dos Estados Americanos.

Dentre eles, vale citar o relatório CP/doc.3842/04, expedido pela SecretáriaGeral da OEA, intitulado Relatório da Secretária-Geral sobre os Direitos Humanos e o Meio Ambiente. Além de uma análise de todos os documentos já expedidos sobre a matéria, o relatório apresenta os avanços do Sistema Interamericano em relação ao meio ambiente, os avanços no sistema das Nações Unidas e o programa de cooperação institucional e de atividades promocionais entre a Comissão Interamericana e a unidade de Desenvolvimento Sustentável e Meio Ambiente.

Vale citar ainda, o CP/CAJP - 1898/02, expedido pela Secretaria Executiva da Comissão Interamericana de Direitos Humanos e que foi apresentado à Comissão de Assuntos Jurídicos e Políticos do Conselho Permanente. O documento relata os alcances da temática de direitos humanos e ambiente no Sistema Interamericano, defendendo, expressamente, a vinculação entre direitos humanos e meio ambiente, nos seguintes dizeres:

\footnotetext{
A Declaração Universal dos Direitos Humanos não faz menção alguma ao meio ambiente. Há fortes razões para se acreditar, no entanto, que ela certamente os mencionaria, se fosse negociada hoje. A inter-relação dos direitos humanos e do meio ambiente vem crescendo. Apesar de até recentemente esses campos terem sido vistos como distintos, a prática cada vez mais os vincula. A tendência é que as declarações sobre cada esfera também sejam cada vez mais amplas, cedendo espaço para que os vínculos se desenvolvam.
}

Há também diversos relatórios que tratam da temática ambiental, são eles: o Relatório da OEA 2000 sobre a Guatemala, em seus Capítulos III \& XI; o Relatório da OEA 2000 sobre o Paraguai, nos Capítulos V \& IX, Relatório da OEA 1999 sobre o Peru, no Capítulo VI; o Relatório Anual de 1997, da Comissão Interamericana de Direitos Humanos, em sua página 46, dentre outros. 
No que tange às resoluções, merecem destaque a AG/RES. 1819 (XXXI-O/01), intitulada "Direitos Humanos e Meio Ambiente", aprovada na terceira sessão plenária, em 2001 e a AG/RES, 1896 (XXXII-O/02) intitulada "Direitos Humanos e Meio Ambiente nas Américas", aprovada na quarta sessão plenária, em 2002.

\subsection{Meio ambiente na jurisprudência do Sistema Interamericano}

Além da farta documentação, a jurisprudência da Corte vem avançando, mesmo que intimamente, sobre o tema. Como bem lembra o professor Cançado Trindade (1993, p. 186), "a proteção do direito a um meio ambiente sadio conta hoje com base não só doutrinárias como também jurisprudenciais".

Partindo desse pressuposto informado pelo professor, vale analisar os dois casos mais emblemáticos do sobredito sistema. Ambos precedentes foram firmados em razão de demandas envolvendo comunidades indígenas:

O primeiro deles, o caso de no 7615, Pueblo Yanomami x Brasil, de 5 de março de 1985, também chamado de Caso Yanomami, envolveu a construção, em 1973, de uma estrada - BR-210 - que passava pelo território Yanomami, e ainda a exploração de recursos minerais, obrigando esse povo a abandonar seu território e procurar abrigo em outros lugares. A Comissão Interamericana constatou violações da Declaração Americana dos Direitos e Deveres do Homem com respeito ao direito à vida, à liberdade e à segurança pessoal e ao direito à preservação da saúde e do bem-estar. ${ }^{20}$

O segundo diz respeito ao caso Comunidade indígena Awas Tingni Mayagna (Sumo) $x$ Nicarágua. A Comissão encaminhou esse caso à Corte Interamericana alegando que o fracasso da demarcação e reconhecimento do território, face à perspectiva do desmatamento sancionado pelo governo nessas terras, constituía uma violação da Convenção Americana. A Corte decidiu, em agosto de 2001, que o Estado violara os artigos 21 e 25 da Convenção Americana, ordenando que o Estado demarcasse as terras dos Awas Tingni. ${ }^{21}$

INTER-AMERICAN COMISSION ON HUMAN RIGHTS. RESOLUTION N ${ }^{\circ} 12 / 85$ Case $\mathrm{N}^{\circ} 7615$ BRAZIL March 5, 1985. Disponível em http://www.cidh.oas.org/annualrep/84.85eng/brazil7615.htm. Acesso em 26 de set. 2011.

21 Corte Interamericana de Derechos Humanos. Caso de la Comunidad Mayagna (Sumo) Awas Tingni Vs. Nicaragua Sentencia de 31 de agosto de 2001. (Fondo, Reparaciones y Costas). Disponível em: http://www. corteidh.or.cr/docs/casos/articulos/Seriec 79 esp.pdf. Acesso em 26 de set 2011. 
Percebe-se que, apesar de não fazer referência ao meio ambiente puramente dito, tais julgados devem ser entendidos como precedentes ambientais, já que o desdobramento dos direitos à informação, de participação e a recursos internos disponíveis e eficazes, por exemplo, representa um importante passo inicial para a construção de medidas de implementação daquele direito.

\section{CONCLUSÃO}

Após a realização das Conferências Internacionais de Estocolmo, Rio e Johanesburgo e a consagração da ideia de que o dano ao meio ambiente pode impactar diversos estados ao mesmo tempo, o direito ao meio ambiente ecologicamente equilibrado foi alçado ao patamar de direito humano internacionalmente protegido, tanto por meio de Convenções, Resoluções e Relatórios, quanto por meio da jurisprudência.

É exatamente neste aspecto, que se verificou a importância do Sistema Interamericano para a consagração do meio ambiente como um direito humano. Isso porque, apesar de incipiente, os precedentes jurisdicionais da Comissão e da Corte comprovam a tendência cada vez maior de vinculação desses temas.

Deve-se ter em mente, que com a realização da Conferência da ONU sobre o Meio Ambiente, no Rio de Janeiro, em 2012, a tendência é de crescimento da regulamentação da questão na esfera internacional e de maior volume de demandas protocolas cuja finalidade será a de proteger o meio ambiente. Por outro lado, é importante que os estados americanos incentivem e promovam tal prática. 


\section{REFERÊNCIAS BIBLIOGRÁFICAS}

COSTA, José Augusto Fontoura e DERANI, Cristiane. Direito Ambiental Internacional. Santos: Leopoldianum, 2001.

DELGADO, Ana Paula Teixeira. O direito ao desenvolvimento na perspectiva da globalização. São Paulo: Renovar, 2001.

HANASHIRO, O. S. M. P. 2001. O Sistema Interamericano de Proteção aos Direitos Humanos. São Paulo, EDUSP, p. 25-32.

MAZZUOLI, Valério de Oliveira. Curso de Direito Internacional Público. $3^{\mathrm{a}} \mathrm{ed}$. São Paulo: Editora Revista dos Tribunais, 2009.

MAZZUOLI, V. de O. 2011. Some Notes on Brazil in the Inter-American Human Rights System. São Paulo, Blog do LFG, acessado em 10/03/2011. Disponível em: < http://www.blogdolfg.com.br/wp-content/ uploads/2011/02/Article-Some-Notes-Inter-American-System-Mazzuoli.pdf $>$.

MAZZUOLI, V. de O. 2011. Os Sistemas Regionais de Proteção dos Direitos Humanos: uma análise comparativa dos sistemas interamericano, europeu e africano. São Paulo: Editora Revista dos Tribunais, 2011. (Coleção Direito e Ciências Afins. V.9).

PADILHA, Norma Sueli. Fundamentos constitucionais do direito ambiental brasileiro. Rio de Janeiro: Campus, 2010.

QUILTER, Peter. Relatório da Secretaria - Geral sobre Cumprimento da AG/RES. 1819 (XXXI-O/01)

- Direitos Humanos e Meio Ambiente. Conselho Permanente da Organização dos Estados Americanos, 2002.

SILVA, José Afonso da. Curso de Direito Constitucional Positivo. 19. ed. São Paulo: Malheiros, 2000 .

SILVA, Solange Teles da. O Direito Ambiental Internacional. Belo Horizonte: Del Rey, 2010. 